\title{
Nutritional status and body composition after 6 months of patients switching from continuous ambulatorial peritoneal dialysis to automated peritoneal dialysis
}

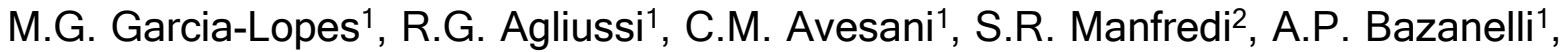 \\ M.A. Kamimura ${ }^{1}$, S.A. Draibe ${ }^{2}$ and L. Cuppari ${ }^{1,2}$ \\ ${ }^{1}$ Programa de Nutrição, ${ }^{2}$ Divisão de Nefrologia, Escola Paulista de Medicina, Universidade Federal de \\ São Paulo, São Paulo, SP, Brasil
}

Correspondence to: L. Cuppari, Rua Pedro de Toledo, 282, 04039-000 São Paulo, SP, Brasil

Fax: +55-11-5572-1862. E-mail: lilian@dis.epm.br

\begin{abstract}
Our objective was to determine if automated peritoneal dialysis (APD) leads to changes in nutritional parameters of patients treated by continuous ambulatory peritoneal dialysis (CAPD). Twenty-six patients (15 males; $50.5 \pm 14.3$ years) were evaluated during CAPD while training for APD and after 3 and 6 months of APD. Body fat was assessed by the sum of skinfold thickness and the other body compartments were assessed by bioelectrical impedance. During the 6-month follow-up, 12 patients gained more than $1 \mathrm{~kg}$ (GW group), 8 patients lost more than $1 \mathrm{~kg}$ (LW group), and 6 patients maintained body weight (MW group). Except for length on dialysis that was longer for the LW group compared with the GW group, no other differences were found between the groups at baseline. After 6 months on APD, the LW group had a reduction in body fat $(24.5 \pm 7.7 \mathrm{vs} 22.1 \pm 7.3 \mathrm{~kg}$; $P=0.01)$, body cell mass $(22.6 \pm 6.2$ vs $21.6 \pm 5.8 \mathrm{~kg}, \mathrm{P}=0.02)$ and phase angle $(5.4 \pm 0.9$ vs $5.1 \pm 0.8$ degrees, $\mathrm{P}=0.004)$. In the GW group, body fat $(25 \pm 7.6$ vs $27.2 \pm 7.6 \mathrm{~kg}, \mathrm{P}=0.001)$ and body cell mass $(20.1 \pm 3.9 \mathrm{vs} 20.8 \pm 4.0 \mathrm{~kg}, \mathrm{P}=0.05)$ were increased. In the present study, different patterns of change in body composition were found. The length of previous dialysis treatment seems to be the most important factor in determining these nutritional modifications.
\end{abstract}

Key words: Chronic kidney disease; Peritoneal dialysis; Body composition; Nutritional parameters

Research supported by Oswaldo Ramos Foundation. M.G. Garcia-Lopes was the recipient of a Master's scholarship from CAPES. Publication supported by FAPESP.

Received August 13, 2007. Accepted November 18, 2008

\section{Introduction}

In the past decade, many patients on continuous ambulatory peritoneal dialysis (CAPD) have been switched to automated peritoneal dialysis (APD) (1). APD offers important advantages over CAPD and has become the first choice for many patients. The potential improvement in the quality of life is one of the most important advantages of this method (2). In fact, APD can greatly reduce the time the patient dedicates daily to his/her treatment, providing more free time for leisure activities and for work (3). Although still controversial, the incidence of peritonitis seems to be lower in APD compared to CAPD probably as the result of reduction of the number of connections needed for treatment (4). Additionally, APD might benefit high transporter patients due to the higher exchange frequencies with shorter dwell times (5).

On the other hand, APD has some disadvantages. Some studies have observed a faster decline in the residual renal function in patients on APD (6). This could, in turn, contribute to the development of anemia (7), inflammation $(8,9)$, malnutrition $(10,11)$, and increase the mortality risk $(12,13)$. Moreover, a greater volume of dialysis fluid is used in APD and hence, a larger glucose load is offered, 
which may have harmful effects on the peritoneal membrane as time on peritoneal dialysis advances (14). If glucose absorption increases, a number of glucose-related metabolic derangements such as hyperinsulinemia, dyslipidemia and obesity may also occur $(15,16)$. In addition, APD may not be the best choice for low transporter patients who can benefit with therapy with long dwells (1). Thus, taking into account these modality-related factors, APD has advantages and disadvantages that can affect the nutritional condition of the patients.

Using nutritional markers, such as body weight, body mass index, serum albumin, and protein equivalent of nitrogen appearance (PNA), only 3 studies have compared the nutritional condition of patients on CAPD with those on APD and have reported no differences between the two modalities (17-19). However, none of these studies analyzed prospectively the effects of APD on nutritional parameters. Thus, the present study evaluated whether APD could lead to changes in the nutritional status and body composition of patients previously treated by CAPD.

\section{Patients and Methods}

\section{Patients}

This study enrolled 26 patients on APD (15 males) from the Dialysis Unit of the Federal University of São Paulo and Oswaldo Ramos Foundation who had been on CAPD. Only patients older than 18 years of age who were on CAPD for at least 3 months and were free of peritonitis for 3 months were included in the study prior to the start of APD. Their mean age was $50.5 \pm 14.3$ years, body mass index was $26.6 \pm 4.9 \mathrm{~kg} / \mathrm{m}^{2}, 17$ patients $(70.8 \%)$ had residual renal function (creatinine clearance $=4.4 \pm 5.6$ $\mathrm{mL} / \mathrm{min}$ ) and the median length of time on CAPD was 11 months (range: 3-60 months). The main causes of chronic kidney disease were diabetes mellitus for 9 patients (34.6\%), hypertensive nephrosclerosis for 5 patients (19.2\%), and chronic glomerulonephritis for 2 patients (7.7\%). The cause of chronic kidney disease was not determined for 10 (38.5\%) patients. Overall, 10 patients $(38.5 \%)$ had diabetes mellitus.

All patients were dialyzed using conventional glucosebased peritoneal dialysis solutions (1.5, 2.5, and 4.25\%). When patients were on CAPD, the majority of them $(76.9 \%$, $\mathrm{N}=20$ ) were doing 4 exchanges per day, with each bag containing 2.0 to $2.5 \mathrm{~L}$. When the patients were transferred to APD, $57.7 \%(\mathrm{~N}=15)$ of them were on continuous cyclic peritoneal dialysis with 1 or 2 additional exchanges during the day with bags of 2.0 to $2.5 \mathrm{~L}$. The remaining patients $(42.3 \%, N=11)$ were on nightly intermittent peritoneal dialysis with an empty peritoneal cavity during the daytime.
The patients were classified as low ( $\mathrm{N}=1,3.8 \%)$, low average $(\mathrm{N}=8,30.9 \%)$, high average $(\mathrm{N}=14,53.8 \%)$, and high $(\mathrm{N}=3,11.5 \%)$ transporters.

This study was approved by the Human Investigation Review Committee of the Federal University of São Paulo and written informed consent was obtained from each subject.

\section{Methods}

Study protocol. This was a prospective study that included patients on CAPD who were evaluated shortly before the start of APD and after 3 and 6 months on APD. All participants were initially submitted to a first interview in order to meet the inclusion criteria, and to obtain informed consent. Their nutritional status, body composition and biochemical parameters were assessed during CAPD, and 3 and 6 months after the beginning of APD.

Nutritional assessment. Nutritional assessment included anthropometric measurements (body weight, height, triceps skinfold thickness, midarm circumference, and body mass index) and PNA, determined using 24-h urinary and dialysate urea, according to National Kidney FoundationDOQI recommendations (20).

Body composition. Body fat was estimated by the sum of skinfold thickness measured at four sites (biceps, triceps, subscapular, and suprailiac). The measurements were performed using the Lange ${ }^{\circledR}$ skinfold caliper (Cambridge Instrument, USA). Body density was calculated using the formula of Durnin and Womersley (21) and the percentage of body fat was then calculated by Siri's equation (22). Lean body mass, total body water, intracellular and extracellular body water, phase angle, and body cell mass were evaluated by bioelectrical impedance (BIA), using a single frequency tetrapolar technique (800A, 50 kHz, model BIA 101 Quantum, RJL Systems, USA). The Fluids \& Nutrition software (version 3.0) was used to calculate the body composition compartments.

All anthropometric and BIA measurements were performed while the patients were with an empty peritoneal cavity and after a careful physical examination to assure that the patients were free of edema.

Biochemical data. Blood samples were drawn after an overnight fast of $12 \mathrm{~h}$. Serum albumin (normal range: 3.4 to $4.8 \mathrm{~g} / \mathrm{dL}$ ) was measured by the bromocresol green method. Serum and dialysate creatinine, urea and glucose were determined by a standard autoanalyzer. The peritoneal glucose absorption was calculated as the difference between the amount of glucose provided by the dialysis fluid and the amount of glucose drained into the dialysate.

Total weekly $\mathrm{Kt} / \mathrm{V}$ urea and creatinine clearance were calculated using standard methods (23). 


\section{Statistical analysis}

Data are reported as means \pm standard deviation for normally distributed variables and as median and ranges for skewed variables not normally distributed. One-way repeated measures analysis (ANOVA) was used to assess changes in laboratory, dialysis and nutritional parameters during follow-up (baseline, 3 and 6 months). Paired Student $t$-test was used to compare the nutritional, laboratory and dialysis parameters between baseline and 6 months in the three groups according to the changes in body weight (gained weight, lost weight and maintained weight). Chisquare test or Fisher exact test was used for categorical variable comparison between groups. Differences with $P$ values $\leq 0.05$ were considered to be statistically significant. Statistical analysis was performed with the SPSS software (version 11.0; SPSS, Inc., USA).

\section{Results}

The laboratory, dialysis, body composition, and nutritional parameters of patients at baseline and during followup are reported in Table 1. A reduction of serum urea and glucose was observed after 6 months on APD. Instilled and drained glucose increased significantly, although no change was seen in absorbed glucose. No other statistically significant changes were found either in the dialysis parameters or in the nutritional and body composition measurements after 6 months on APD. Although body weight did not change significantly during follow-up, 12 patients (46.1\%) gained more than $1 \mathrm{~kg}$ [median (range); GW group: $2.1 \mathrm{~kg}$ (1.0 to $7.7 \mathrm{~kg})$ ], 8 patients $(30.8 \%)$ lost more than $1 \mathrm{~kg}$ [LW group: $-3.2 \mathrm{~kg}(-6.8$ to $-1.6 \mathrm{~kg})$ ] and 6 patients (23.1\%) maintained their body weight [MW group: $0.3 \mathrm{~kg}$

Table 1. Laboratory, dialysis, body composition, and nutritional parameters during the follow-up of patients who were on continuous ambulatory peritoneal dialysis (CAPD) and were switched to automated peritoneal dialysis (APD).

\begin{tabular}{|c|c|c|c|c|}
\hline & CAPD & APD (3 months) & APD (6 months) & $\mathrm{P}$ \\
\hline \multicolumn{5}{|l|}{ Laboratory parameters } \\
\hline Serum creatinine (mg/dL) & $8.7 \pm 3.9$ & $8.7 \pm 3.1$ & $8.7 \pm 3.2$ & \\
\hline Serum urea $(\mathrm{mg} / \mathrm{dL})$ & $105.9 \pm 27.0$ & $92.5 \pm 27.2$ & $92.7 \pm 25.9$ & $0.03^{*}$ \\
\hline Serum glucose $(\mathrm{mg} / \mathrm{dL})^{a}$ & $172.6 \pm 82.8$ & $121.8 \pm 60.1$ & $137.4 \pm 75.8$ & $0.01^{*}$ \\
\hline \multicolumn{5}{|l|}{ Dialysis parameters } \\
\hline Dialysate glucose (g/day) & $172.6 \pm 28.8$ & $266.8 \pm 77.6$ & $279.2 \pm 73.1$ & $0.001^{*}$ \\
\hline Drained glucose $(\mathrm{g} / \mathrm{day})^{\mathrm{b}}$ & $62.2 \pm 24.9$ & $128.2 \pm 38.9$ & $137.3 \pm 53.4$ & $0.001^{*}$ \\
\hline Absorbed glucose $(\mathrm{g} / \text { day })^{\mathrm{b}}$ & $112.1 \pm 28.9$ & $132.7 \pm 54.7$ & $135.9 \pm 60.3$ & \\
\hline \multicolumn{5}{|l|}{$\mathrm{Kt} / \mathrm{V}$ urea (weekly) ${ }^{\mathrm{b}}$} \\
\hline Total & $2.50 \pm 0.79$ & $2.46 \pm 0.80$ & $2.41 \pm 0.68$ & \\
\hline Peritoneal & $1.81 \pm 0.41$ & $1.92 \pm 0.61$ & $1.91 \pm 0.50$ & \\
\hline Renal & $0.69 \pm 0.74$ & $0.54 \pm 0.56$ & $0.50 \pm 0.53$ & \\
\hline Residual renal function $(\mathrm{CrCl} \mathrm{mL} / \mathrm{min})^{\mathrm{C}}$ & $4.4 \pm 5.6$ & $3.5 \pm 4.1$ & $3.2 \pm 4.3$ & \\
\hline \multicolumn{5}{|l|}{ Body composition and nutritional parameters } \\
\hline Weight (kg) & $69.5 \pm 11.0$ & $69.5 \pm 10.5$ & $69.8 \pm 11.4$ & \\
\hline Body mass index $\left(\mathrm{kg} / \mathrm{m}^{2}\right)$ & $26.6 \pm 4.9$ & $27.0 \pm 5.0$ & $26.7 \pm 5.4$ & \\
\hline MAMC $(\mathrm{cm})$ & $23.5 \pm 3.2$ & $23.9 \pm 3.1$ & $23.9 \pm 3.9$ & \\
\hline Lean body mass $(\mathrm{kg})$ & $48.9 \pm 10.7$ & $48.2 \pm 10.1$ & $48.3 \pm 10.0$ & \\
\hline Body fat $(\mathrm{kg})^{\mathrm{b}}$ & $23.7 \pm 7.2$ & $24.0 \pm 7.6$ & $24.4 \pm 7.4$ & \\
\hline Total body water $(L)$ & $36.8 \pm 7.0$ & $36.0 \pm 6.6$ & $36.1 \pm 6.4$ & \\
\hline Intracellular water (L) & $9.4 \pm 4.7$ & $19.2 \pm 4.7$ & $19.4 \pm 4.4$ & \\
\hline Extracellular water (L) & $17.4 \pm 2.9$ & $16.9 \pm 2.7$ & $16.7 \pm 2.8$ & \\
\hline Body cell mass $(\mathrm{kg})$ & $21.3 \pm 5.2$ & $21.0 \pm 5.2$ & $21.3 \pm 4.8$ & \\
\hline Phase angle (degrees) & $5.2 \pm 1.0$ & $5.1 \pm 1.2$ & $5.4 \pm 1.1$ & \\
\hline PNA $\left(g \cdot \mathrm{kg}^{-1} \cdot \mathrm{day}^{-1}\right)^{\mathrm{d}}$ & $0.70 \pm 0.09$ & $0.68 \pm 0.14$ & $0.66 \pm 0.14$ & \\
\hline Serum albumin $(\mathrm{g} / \mathrm{dL})^{e}$ & $3.7 \pm 0.6$ & $4.0 \pm 1.0$ & $3.8 \pm 0.6$ & \\
\hline
\end{tabular}

Data are reported as means \pm standard deviation for $N=26$, except for ${ }^{a} \mathrm{~N}=13 ;{ }^{b} \mathrm{~N}=23 ;{ }^{c} \mathrm{~N}=17 ;{ }^{d} \mathrm{~N}=22 ;{ }^{e} \mathrm{~N}=16$. $\mathrm{CrCl}=\mathrm{creatinine}$ clearance. $\mathrm{MAMC}=$ midarm muscle circumference. $\mathrm{PNA}=$ protein equivalent of nitrogen appearance. Phase angle $=$ relation between the direct measures of resistance and reactance (phase angle $=$ arc-tangent reactance/resistance $\left.\times 180^{\circ} / \pi\right)(32)$. Kt $/ \mathrm{V}=\mathrm{measure}$ of the amount of plasma cleared of urea multiplied by time $(\mathrm{K} \times \mathrm{t})$ divided by the urea distribution volume $(\mathrm{V})$. Data were analyzed statistically by one-way repeated measures analysis (ANOVA). *Significant differences refer to CAPD compared to 6 months APD. No significant differences were found compared to 3 months APD. 
$(-0.4$ to $0.9 \mathrm{~kg})$ ] after 6 months on APD. In view of the large differences in the body weight changes, statistical analysis was carried out comparing these groups. No differences were observed among the 3 groups in relation to the characteristics of membrane transport, number of patients on continuous cyclic peritoneal dialysis and nightly intermittent peritoneal dialysis, and demographic and dialysis parameters before APD was initiated (data not shown). The percentage of diabetic patients in each group was also similar (GW group: $41.7 \%$ vs LW group: $37.5 \%$ vs MW group: $33.3 \%$; $P=0.94$ ). When the baseline factors that could influence the changes in body weight were compared between the GW and LW groups, no differences were found except for the length of CAPD that was significantly longer in the group that lost weight [median (range); GW group: 10 months (3-21 months) vs LW group: 17 months (10-46 months); $P=0.01]$.

As shown in Tables 2 and 3 , no differences were

Table 2. Body composition and nutritional parameters according to the changes of body weight during the follow-up of patients who were on continuous ambulatory peritoneal dialysis (CAPD) and were switched to automated peritoneal dialysis (APD) (N = 26).

\begin{tabular}{|c|c|c|c|c|c|c|c|c|c|}
\hline \multirow{2}{*}{$\begin{array}{l}\text { Body composition and } \\
\text { nutritional parameters }\end{array}$} & \multicolumn{3}{|c|}{ Gained weight $(\mathrm{N}=12)$} & \multicolumn{3}{|c|}{ Lost weight $(\mathrm{N}=8)$} & \multicolumn{3}{|c|}{ Maintained weight $(\mathrm{N}=6)$} \\
\hline & CAPD & $\begin{array}{c}\text { APD } \\
\text { (6 months) }\end{array}$ & $P$ & CAPD & $\begin{array}{c}\text { APD } \\
\text { (6 months) }\end{array}$ & $P$ & CAPD & $\begin{array}{c}\text { APD } \\
\text { (6 months) }\end{array}$ & $P$ \\
\hline Weight (kg) & $69.4 \pm 10.7$ & $72.3 \pm 11.2$ & & $70.1 \pm 14.1$ & $66.4 \pm 13.7$ & & $69.0 \pm 8.5$ & $69.3 \pm 8.3$ & \\
\hline MAMC $(\mathrm{cm})$ & $23.2 \pm 3.8$ & $23.7 \pm 4.9$ & & $23.9 \pm 2.7$ & $23.8 \pm 2.6$ & & $24.2 \pm 2.7$ & $24.7 \pm 2.5$ & \\
\hline Lean body mass $(\mathrm{kg})$ & $46.5 \pm 9.0$ & $47.4 \pm 8.2$ & & $50.6 \pm 13.0$ & $49.1 \pm 12.6$ & & $53.1 \pm 11.2$ & $50.7 \pm 11.1$ & $0.01^{*}$ \\
\hline Body fat $(\mathrm{kg})$ & $25.0 \pm 7.6$ & $27.2 \pm 7.6$ & $0.001^{*}$ & $24.5 \pm 7.7$ & $22.1 \pm 7.3$ & $0.01^{*}$ & $19.5 \pm 5.2$ & $20.8 \pm 5.4$ & \\
\hline Total body water $(\mathrm{L})$ & $35.4 \pm 5.6$ & $35.8 \pm 5.2$ & & $38.1 \pm 8.8$ & $36.6 \pm 8.5$ & & $39.0 \pm 7.3$ & $36.8 \pm 6.9$ & $0.01^{*}$ \\
\hline Intracellular water (L) & $18.6 \pm 3.5$ & $19.0 \pm 3.6$ & $0.04^{*}$ & $20.7 \pm 5.7$ & $19.7 \pm 5.3$ & $0.02^{*}$ & $21.2 \pm 5.9$ & $20.8 \pm 5.3$ & \\
\hline Extracellular water $(\mathrm{L})$ & $17.0 \pm 2.8$ & $16.8 \pm 2.6$ & & $17.4 \pm 3.6$ & $16.9 \pm 3.5$ & & $17.8 \pm 2.3$ & $16.0 \pm 2.5$ & $0.04^{*}$ \\
\hline Body cell mass (kg) & $20.1 \pm 3.9$ & $20.8 \pm 4.0$ & $0.05^{*}$ & $22.6 \pm 6.2$ & $21.6 \pm 5.8$ & $0.02^{*}$ & $23.3 \pm 6.5$ & $22.8 \pm 5.8$ & \\
\hline Phase angle (degrees) & $5.2 \pm 1.1$ & $5.4 \pm 1.2$ & & $5.4 \pm 0.9$ & $5.1 \pm 0.8$ & $0.004^{*}$ & $4.9 \pm 1.1$ & $5.5 \pm 1.3$ & \\
\hline PNA $\left(\mathrm{g} \cdot \mathrm{kg}^{-1} \cdot \mathrm{day}^{-1}\right)$ & $0.71 \pm 0.09$ & $0.71 \pm 0.11$ & & $0.74 \pm 0.07$ & $0.54 \pm 0.06$ & $0.001^{*}$ & $0.63 \pm 0.10$ & $0.70 \pm 0.19$ & \\
\hline Serum albumin (g/dL) & $3.7 \pm 0.5$ & $3.7 \pm 0.3^{a}$ & & $3.7 \pm 0.6$ & $3.6 \pm 0.8$ & & $3.5 \pm 0.7$ & $3.9 \pm 0.7$ & \\
\hline
\end{tabular}

Data are reported as means \pm standard deviation for $N=26$, except ${ }^{a} \mathrm{~N}=7$. MAMC $=$ midarm muscle circumference. $\mathrm{PNA}=$ protein equivalent of nitrogen appearance. Phase angle $=$ relation between the direct measures of resistance and reactance (phase angle $=$ arc-tangent reactance/resistance $\times 180 \%$ ) (32). Data were analyzed statistically by the paired Student $t$-test. *CAPD vs APD (6 months).

Table 3. Laboratory and dialysis parameters according to the changes of body weight during the follow-up of patients who were on continuous ambulatory peritoneal dialysis (CAPD) and were switched to automated peritoneal dialysis (APD).

\begin{tabular}{|c|c|c|c|c|c|c|c|c|c|}
\hline & \multicolumn{3}{|c|}{ Gained weight $(N=12)$} & \multicolumn{3}{|c|}{ Lost weight $(\mathrm{N}=8)$} & \multicolumn{3}{|c|}{ Maintained weight $(\mathrm{N}=6)$} \\
\hline & CAPD & $\begin{array}{c}\text { APD } \\
\text { (6 months) }\end{array}$ & $\mathrm{P}$ & CAPD & $\begin{array}{c}\text { APD } \\
\text { (6 months) }\end{array}$ & $P$ & CAPD & $\begin{array}{c}\text { APD } \\
\text { (6 months) }\end{array}$ & $P$ \\
\hline \multicolumn{10}{|l|}{ Laboratory parameters } \\
\hline Serum creatinine $(\mathrm{mg} / \mathrm{dL})$ & $7.5 \pm 3.2$ & $8.2 \pm 2.3$ & & $10.9 \pm 4.6$ & $9.4 \pm 3.4$ & & $7.8 \pm 3.3$ & $9.2 \pm 4.7$ & \\
\hline Serum urea $(\mathrm{mg} / \mathrm{dL})$ & $95.3 \pm 20.9$ & $99.3 \pm 20.5$ & & $119.5 \pm 32.7$ & $73.9 \pm 20.5$ & $0.004^{*}$ & $109.2 \pm 29.5$ & $104.3 \pm 31.5$ & \\
\hline \multicolumn{10}{|l|}{ Dialysis parameters } \\
\hline Dialysate glucose (g/day) & $163.8 \pm 36.5$ & $261.5 \pm 55.7$ & $<0.001^{*}$ & $178.4 \pm 18.7$ & $280.3 \pm 86.9$ & $0.008^{*}$ & $182.5 \pm 19.4$ & $313.3 \pm 84.8$ & $0.02^{*}$ \\
\hline Drained glucose (g/day) & $70.9 \pm 20.0$ & $126.5 \pm 51.9$ & $0.01^{*}$ & $59.6 \pm 30.8$ & $138.1 \pm 44.8$ & $0.009^{*}$ & $46.6 \pm 21.6$ & $159.8 \pm 70.8$ & $0.02^{*}$ \\
\hline Absorbed glucose (g/day) & $97.8 \pm 24.6$ & $136.9 \pm 55.1$ & & $116.4 \pm 31$ & $128.7 \pm 56.3$ & & $137.4 \pm 15.1$ & $143.7 \pm 86.5$ & \\
\hline \multicolumn{10}{|l|}{$\mathrm{Kt} / \mathrm{V}$ urea (weekly) } \\
\hline Total & $2.54 \pm 0.74$ & $2.55 \pm 0.77$ & & $2.46 \pm 0.98$ & $2.37 \pm 0.72$ & & $2.49 \pm 0.77$ & $2.16 \pm 0.41$ & \\
\hline Peritoneal & $1.79 \pm 0.40$ & $1.97 \pm 0.38$ & & $1.93 \pm 0.44$ & $2.03 \pm 0.59$ & & $1.68 \pm 0.43$ & $1.62 \pm 0.58$ & \\
\hline Renal & $0.75 \pm 0.82$ & $0.59 \pm 0.69$ & & $0.52 \pm 0.67$ & $0.34 \pm 0.40$ & & $0.81 \pm 0.75$ & $0.54 \pm 0.31$ & \\
\hline
\end{tabular}

Data are reported as means \pm standard deviation for $\mathrm{N}=26 \mathrm{Kt} / \mathrm{V}=$ measure of the amount of plasma cleared of urea multiplied by time $(\mathrm{K} \times \mathrm{t})$ divided by the urea distribution volume $(\mathrm{V})$. Data were analyzed statistically by the paired Student $t$-test. ${ }^{*} \mathrm{CAPD} v s \mathrm{APD}(6$ months). 
observed among the groups regarding body composition, nutritional and laboratory parameters at baseline. When comparing the body composition and nutritional parameters during the follow-up (Table 2), the patients who gained body weight increased significantly body fat $(2.2 \pm$ $1.5 \mathrm{~kg})$, intracellular water $(0.7 \pm 1.0 \mathrm{~L})$ and body cell mass $(0.7 \pm 1.1 \mathrm{~kg})$, while those patients who lost body weight reduced significantly body fat $(-2.3 \pm 1.7 \mathrm{~kg})$, intracellular water $(-1.0 \pm 0.8 \mathrm{~L})$, body cell mass $(-1.1 \pm 0.9 \mathrm{~kg})$ and phase angle $(-0.3 \pm 0.2)$. The group of patients who maintained body weight had a significant decrease in lean body mass $(-2.4 \pm 1.4 \mathrm{~kg})$, and total $(-2.2 \pm 1.5 \mathrm{~L})$ and extracellular body water $(-1.8 \pm 1.6 \mathrm{~kg})$. In addition, a tendency to increased body fat $(1.3 \pm 1.4 \mathrm{~kg})$ and serum albumin $(0.4 \pm$ $0.4 \mathrm{~g} / \mathrm{dL}$ ) was observed in this group. The protein intake estimated by PNA was reduced only in the group that lost body weight.

As can be seen in Table 3, a reduction of serum urea was observed in the group that lost body weight. The amount of instilled glucose and drained glucose was higher in all groups after 6 months, but only patients who gained body weight had a tendency to higher glucose absorption.

\section{Discussion}

In the present study, we determined whether APD leads to changes in the nutritional status and body composition parameters in patients previously treated by CAPD. Overall, no significant changes were observed. However, in a detailed analysis, we observed that the majority of the patients $(77 \%)$ had increased or decreased body weight in the 6-month follow-up period. Thus, we performed the analysis by dividing the patients into groups according to changes in body weight. In fact, using this approach, we found different patterns of changes in the body compartments, according to the changes in body weight. The different patterns observed were not associated with demographics, nutritional, biochemical, or dialytic characteristics at CAPD, except for time on CAPD that was significantly shorter in the patients who gained body weight compared with those who lost body weight. Regardless of the peritoneal dialysis modality, the relationship between length of time on peritoneal dialysis and changes in body compartments, especially body fat compartment, has already been shown. The majority of the studies showed that whereas lean body mass seems to be rather stable, body fat and body weight increase considerably in a short time on peritoneal dialysis (24-26). On the other hand, Davies et al. (27) reported that following an initial improvement of body weight and mid-arm circumference, a decline may occur after 2 years of peritoneal dialysis. Indeed, several studies suggest that during long-term peritoneal dialysis a gradual deterioration in nutritional status may occur with a decrease in lean body mass $(25,27)$. It is of note that none of these studies analyzed whether the peritoneal dialysis modality, CAPD or APD, could be associated with changes of body weight.

When a detailed analysis of changes in body compartments was performed in our study, we observed that the group that gained body weight showed no significant changes in total body water and lean body mass, while body cell mass (BCM) and body fat increased significantly. It is generally assumed that the accumulation of body fat is related to the glucose absorption from the dialysate. Particularly in APD, a larger amount of glucose is offered as a consequence of a greater dialysate volume used. In fact, in our study the amount of glucose offered was in mean $65 \%$ higher with APD compared to CAPD in the whole group of patients. However, the drained glucose also increased, probably due to the greater number of exchanges with shorter dwell times. As a result, the absorbed glucose did not change when the whole sample was considered, but in the group of patients that gained body weight a tendency of higher glucose absorption was found. This finding could explain, at least in part, the accumulation of body fat in this group. An increase in food intake could also be associated with body fat accumulation; however, this seems not to be the case in our study since protein intake estimated by PNA, a surrogate marker of food consumption, did not change in this group.

In the group of patients who lost body weight, the decrease in body fat was accompanied by a significant reduction in $\mathrm{BCM}$, phase angle and intracellular water. Using total body potassium method, Johansson et al. (25) found similar results regarding BCM during the second and third year of peritoneal dialysis. BCM is a marker for combined somatic and visceral protein stores and is considered the most metabolically active body compartment that is highly sensitive to changes in muscle mass $(25,28)$. Therefore, the reduction in BCM could indicate a reduction of protein stores of these patients, even though no changes in lean body mass were observed. The quantification of $B C M$ is difficult because reliable methods such as neutron activation analysis or total body potassium are costly and not widely available. In our study, BIA was the method used to estimate BCM. The strong correlation between $\mathrm{BCM}$ assessed by BIA with reference methods has already been demonstrated in dialysis patients (28).

The reasons for the reduction in body fat and BCM cannot be fully elucidated in this study. Factors widely recognized to worsen nutritional status such as decline of residual renal function and $\mathrm{Kt} / \mathrm{V}$ urea did not change in 
these patients. Only the longer time on peritoneal dialysis and the reduction of protein intake could explain the reduction of body compartments in this group. However, we cannot exclude the possible role of other factors not analyzed in the present study such as infections, chronic inflammation, other co-morbid conditions, and protein loss into the dialysate. The reduction in BCM was accompanied by a reduction of phase angle, which has been pointed out as an indicator of cell membrane integrity. Previous studies reported that low phase angle was associated with increased mortality in hemodialysis patients (29), with lower indexes of nutritional status $(29,30)$ and with lower $\mathrm{BCM}$ and intracellular water in hemodialysis and peritoneal dialysis patients (31). Therefore, the reduction of $\mathrm{BCM}$ and phase angle might be a sign of worse prognosis for the patients who lost body weight.

In spite of the small number of patients in the group that maintained body weight, it is important to note that after 6 months on APD, changes in body compartments were diverse as compared with those patients who gained or lost body weight. Body water was the compartment that suffered modifications the most in these patients. A significant reduction in extracellular water occurred and as a consequence, total body water and lean body mass also decreased associated with increased serum albumin. As 5 of 6 patients in this group were high or high average transporters, we can speculate that this might explain the reduction of body water when they were switched to APD.

The lack of a control group constituted by patients followed on CAPD makes it difficult to affirm whether the changes occurred as a consequence of APD or were the result of the peritoneal dialysis per se. In addition, since our sample was constituted by patients undergoing dialysis for different periods of time, we can not distinguish the contribution of peritoneal dialysis modality or dialysis vintage on the modification found.

This study provides evidence that patients initiating APD may have different patterns of change in body compartments, which seems to be dependent on the previous duration of CAPD. Moreover, it is of note that simple nutritional assessment methods, such as anthropometry and $\mathrm{BIA}$, were able to detect these modifications.

\section{References}

1. Twardowski ZJ. Influence of different automated peritoneal dialysis schedules on solute and water removal. Nephrol Dial Transplant 1998; 13 (Suppl 6): 103-111.

2. de Wit GA, Merkus MP, Krediet RT, de Charro FT. A comparison of quality of life of patients on automated and continuous ambulatory peritoneal dialysis. Perit Dial Int 2001; 21: 306-312.

3. Bro S, Bjorner JB, Tofte-Jensen P, Klem S, Almtoft B, Danielsen $\mathrm{H}$, et al. A prospective, randomized multicenter study comparing APD and CAPD treatment. Perit Dial Int 1999; 19: 526-533.

4. Rodriguez-Carmona A, Perez FM, Garcia FT, Fernandez $\mathrm{RC}$, Valdes F. A comparative analysis on the incidence of peritonitis and exit-site infection in CAPD and automated peritoneal dialysis. Perit Dial Int 1999; 19: 253-258.

5. Correa-Rotter R. APD in the developing world: is there a future? Semin Dial 2002; 15: 385-387.

6. Hiroshige K, Yuu K, Soejima M, Takasugi M, Kuroiwa A. Rapid decline of residual renal function in patients on automated peritoneal dialysis. Perit Dial Int 1996; 16: 307-315.

7. Wang AY, Wang M, Woo J, Law MC, Chow KM, Li PK, et al. A novel association between residual renal function and left ventricular hypertrophy in peritoneal dialysis patients. Kidney Int 2002; 62: 639-647.

8. Wang AY, Wang M, Woo J, Lam CW, Lui SF, Li PK, et al. Inflammation, residual kidney function, and cardiac hypertrophy are interrelated and combine adversely to enhance mortality and cardiovascular death risk of peritoneal dialysis patients. J Am Soc Nephrol 2004; 15: 2186-2194

9. Chung $\mathrm{SH}$, Heimburger $\mathrm{O}$, Stenvinkel $\mathrm{P}$, Bergstrom J,
Lindholm B. Association between inflammation and changes in residual renal function and peritoneal transport rate during the first year of dialysis. Nephrol Dial Transplant 2001; 16: $2240-2245$.

10. Jones MR. Etiology of severe malnutrition: results of an international cross-sectional study in continuous ambulatory peritoneal dialysis patients. Am J Kidney Dis 1994; 23: 412-420.

11. Szeto CC, Lai KN, Wong TY, Law MC, Leung CB, Yu AW, et al. Independent effects of residual renal function and dialysis adequacy on nutritional status and patient outcome in continuous ambulatory peritoneal dialysis. Am J Kidney Dis 1999; 34: 1056-1064.

12. Maiorca R, Brunori G, Zubani R, Cancarini GC, Manili L, Camerini $\mathrm{C}$, et al. Predictive value of dialysis adequacy and nutritional indices for mortality and morbidity in CAPD and HD patients. A longitudinal study. Nephrol Dial Transplant 1995; 10: 2295-2305.

13. Rocco M, Soucie JM, Pastan S, McClellan WM. Peritoneal dialysis adequacy and risk of death. Kidney Int 2000; 58: 446-457.

14. Davies SJ, Phillips L, Naish PF, Russell GI. Peritoneal glucose exposure and changes in membrane solute transport with time on peritoneal dialysis. J Am Soc Nephrol 2001; 12: 1046-1051.

15. Lindholm B, Bergstrom J. Nutritional aspects of CAPD. In: Gokal R (Editor), Continuous ambulatory peritoneal dialysis. Edinburgh: Churchill Livingstone; 1986. p 228.

16. Gokal R, Ramos JM, McGurk J, Ward MK, Kerr DNS. Hyperlipidemia in patients on continuous ambulatory perito- 
neal dialysis. In: Gahl GM, Kessel M, Nolph KD (Editors), Advances in peritoneal dialysis. Amsterdam: Excerpta Medica; 1981. p 430

17. Gao H, Lew SQ, Bosch JP. Biochemical parameters, nutritional status and efficiency of dialysis in CAPD and CCPD patients. Am J Nephrol 1999; 19: 7-12.

18. Dumler F, Galan M, Cruz C. Impact of peritoneal dialysis modality on nutritional and biochemical parameters. Adv Perit Dial 1996; 12: 298-301.

19. Abdo F, Clemente L, Davy J, Grant J, Ladouceur D, Morton AR. Nutritional status and efficiency of dialysis in CAPD and CCPD patients. Adv Perit Dial 1993; 9: 76-79.

20. National Kidney Foundation. Clinical practice guidelines for nutrition in chronic renal failure. K/DOQI. Am J Kidney Dis 2000; 35: S1-S140.

21. Durnin JV, Womersley J. Body fat assessed from total body density and its estimation from skinfold thickness: measurements on 481 men and women aged from 16 to 72 years. $\mathrm{Br}$ J Nutr 1974; 32: 77-97.

22. Siri WE. Body composition from fluid spaces and density: analysis of methods. In: Brozek J, Henschel A (Editors), Techniques for measuring body composition. Washington: National Research Council; 1961. p 223-244.

23. Nolph KD, Moore HL, Twardowski ZJ, Khanna R, Prowant $\mathrm{B}$, Meyer $\mathrm{M}$, et al. Cross-sectional assessment of weekly urea and creatinine clearances in patients on continuous ambulatory peritoneal dialysis. ASAIO J 1992; 38: M139M142.

24. Jager KJ, Merkus MP, Huisman RM, Boeschoten EW, Dekker FW, Korevaar JC, et al. Nutritional status over time in hemodialysis and peritoneal dialysis. J Am Soc Nephrol
2001; 12: 1272-1279.

25. Johansson AC, Samuelsson O, Haraldsson B, Bosaeus I, Attman PO. Body composition in patients treated with peritoneal dialysis. Nephrol Dial Transplant 1998; 13: 15111517.

26. Boeschoten EW, Zuyderhoudt FMJ, Krediet RT, Arisz L. Changes in weight and lipid concentrations during CAPD treatment. Perit Dial Int 1988; 8: 19-24.

27. Davies SJ, Phillips L, Griffiths AM, Russell LH, Naish PF, Russell Gl. What really happens to people on long-term peritoneal dialysis? Kidney Int 1998; 54: 2207-2217.

28. Chertow GM, Lowrie EG, Wilmore DW, Gonzalez J, Lew $\mathrm{NL}$, Ling J, et al. Nutritional assessment with bioelectrical impedance analysis in maintenance hemodialysis patients. J Am Soc Nephrol 1995; 6: 75-81.

29. Maggiore Q, Nigrelli S, Ciccarelli C, Grimaldi C, Rossi GA, Michelassi C. Nutritional and prognostic correlates of bioimpedance indexes in hemodialysis patients. Kidney Int 1996; 50: 2103-2108.

30. Passadakis P, Sud K, Dutta A, Singhal M, Pettit J, Chatalalsingh $C$, et al. Bioelectrical impedance analysis in the evaluation of the nutritional status of continuous ambulatory peritoneal dialysis patients. Adv Perit Dial 1999; 15: 147-152.

31. Jha V, Jairam A, Sharma MC, Sakhuja V, Piccoli A, Parthasarathy S. Body composition analysis with bioelectric impedance in adult Indians with ESRD: comparison with healthy population. Kidney Int 2006; 69: 1649-1653.

32. Baumgartner RN, Chumlea WC, Roche AF. Bioelectric impedance phase angle and body composition. Am J Clin Nutr 1988; 48: 16-23. 